\title{
A BALADA DO MAR SALGADO. VIAGEM FILMADA POR PAISAGENS SEM HOMENS
}

\author{
Maria do CARMo Piçarra ${ }^{1}$
}

\begin{abstract}
RESUMO - Neste artigo procuro analisar porque é que o filme I cruzeiro de férias às colónias ocidentais, encomendado ao prestigiado fotógrafo de arte San Payo para registar o "primeiro cruzeiro de soberania" organizado pela Agência Geral das Colónias, foi projectado uma única vez durante o Estado Novo. Filme de viagens, um subgénero do cinema colonial de propaganda, é uma das primeiras obras de propaganda oficial com a qual se pretende projectar a ideia de que "Portugal não é um país pequeno": (re)construir o país através de um novo mapa do império, portanto. Filme-sintoma de uma "cultura de mobilidade", identificada por Jean Brunhes, quer atestar o domínio do espaço imperial através das novas tecnologias da comunicação. Inconsciente desse fenómeno, da aceleração, terá sido vítima da desintegração do olhar sobre o quotidiano das colónias? Ter-lhe-á faltado, para cumprir o desígnio de projectar a grandeza da nação, um movimento, mais íntimo, da contemplação para a compaixão (Orlando Ribeiro)?
\end{abstract}

Palavras-chave: Cinema colonial, mapa imperial, nação, filme de viagens, propaganda.

\begin{abstract}
THE BALlAD OF THE SAlt SEA: CINEMATOGRAPHiC TRAVEL THROUgh LANDSCAPES Without MEN. This paper analyses why the film $1^{\circ}$ cruzeiro de férias às colónias ocidentais (First Holiday Cruise to the Western Colonies), commissioned to the noted art photographer San Payo, was projected only once during the Estado Novo. This voyage movie, subgenre of colonial cinematic propaganda, is one of the first works of official propaganda intended to show that "Portugal is not a small country": therefore, to (re)build the country through a new imperial map. This film is symptomatic of "mobility culture", identified by Jean Brunhes; its purpose is to testify to the rule of imperial space through new communication technologies. Unaware of this phenomenon of acceleration, this movie may have been a victim of the shattered vision of day-to-day life in the colo-
\end{abstract}

1 Maria do Carmo Piçarra é investigadora de Pós-Doutoramento no Centro de Estudos Comunicação e Sociedade na Universidade do Minho e no Centre for Film Aesthetics and Cultures, da Universidade de Reading. É investigadora integrada do CEC-FLUL - Universidade de Lisboa, professora externa convidada no ISCTE-IUL e editora da ANIKI - Revista Portuguesa da Imagem em Movimento. As suas publicações incidem sobre propaganda e censura ao cinema, cinema militante e cinema colonial. E-mail: carmoramos@gmail.com 
nies. To fulfil its design to project the nations' greatness, it might have lacked an even more intimate movement that would behold compassion (Orlando Ribeiro)?

Keywords: Colonial cinema, imperial map, nation, travel movie, propaganda.

\section{INTRODUÇÃO}

Em 1935 Manuel Alves San Payo (1890-1974) já era um fotógrafo de arte com notoriedade em Portugal mas só no Brasil, para onde emigrara por volta de 1909, realizara filmesi. Pouco se sabe destas obras mas a sua realização e o reconhecimento do talento de San Payo como retratista terá motivado o convite que lhe foi feito por O mundo português (1934-1947), publicação da Agência Geral das Colónias (AGC) e do Secretariado da Propaganda Nacional (SPN), para filmar o I cruzeiro de férias às colónias ocidentais. Subjacente ao convite esteve a presunção de que San Payo dominava a linguagem cinematográfica como dominava a fotográfica. Se a presunção não falhou, até porque San Payo foi auxiliado por um director de fotografia experimentado, Artur Costa de Macedo (1894-1966) ${ }^{i 1}$, o certo é que o filme da viagem foi projectado apenas uma vez, no S. Luiz, em Lisboa, a 29 de Junho de 1936. Num período de escassez de imagens em movimento das colónias, e dados os custos elevados do cinema, a que se deveu, então, a singularidade da projecção, e, ainda assim, só para os participantes no cruzeiro? Terá sido porque o filme ficou aquém do objectivo proposto: projectar a imensidão da nação e o domínio dos avanços tecnológicos que permitiam o controlo do espaço "aquém e além-mar"?

\section{II. “PORTUGAL NÃO É UM PAÍS PEQUENO” PROJECTA-SE EM GRANDE ECRÃ}

Recuemos para contextualizar a novidade do esforço para usar o cinema para "propagandear" as colónias. A faceta colonial de Portugal fora projectada cinematograficamente na Exposição Ibero-americana de Sevilha (1929), na Exposição Internacional e Colonial de Antuérpia (1930) e na Exposição Colonial de Paris (1931). Para mostrar não só as colónias, mas também o domínio das novas tecnologias da comunicação nas exposições internacionais, o Agente Geral das Colónias, Armando Cortesão, encomendara filmes sobre os territórios africanos a três equipas de cineastas tendo a produção beneficiado do apoio financeiro e logístico de empresas privadas e da administração colonial localiii. Má qualidade da fotografia, iluminação e enquadramento, ausência de sentido artístico e científico, titulação incorrecta e reveladora de mau conhecimento da geografia e etnografia, foram, porém, críticas feitas aos filmes ${ }^{\text {iv }}$.

Como se articulou então a utilização do cinema com os desígnios imperiais do regime? Se a Primeira República não se interessou muito pelo cinema - o que é comprovado pela escassa legislação e inexistência de apoios directos - há que assinalar o recurso 
ao seu potencial propagandista para gerar unidade em torno da participação na guerra. Tal não foi uma originalidade portuguesa. Em Inglaterra e França sucederam-se então os primeiros esforços organizados pelo Estado para a divulgação de doutrinas usando o cinema, o que terá servido como modelo. Foi o ministro da Guerra Norton de Matos (1867-1955) a criar a Secção Fotográfica e Cinematográfica do Exército (SFCE), através de despacho de 12 de Janeiro de 1917, duas semanas antes da partida para a Flandres da

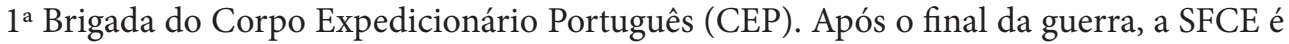
transformada na Direcção dos Serviços Gráficos do Exército, através do Decreto n 5935 , de 28 de Junho de 1919, sobrevivendo a duas mudanças de regime: da I República para o Estado Novo, na sequência do golpe militar de 1926, e deste para a democracia parlamentar, após a revolução de 25 de Abril de 1974.

O uso propagandista do cinema iniciado pelos militares alargou-se. Enquanto Armindo Monteiro é responsável pela pasta das colónias, entre 1931 e 1935, multiplicam-se eventos de projecção do império, sendo os mais importantes fixados pelo cinema: a participação nas exposições internacionais da época, não obstante a crise financeira; a Conferência Imperial Colonial, a I Exposição Colonial Portuguesa no Portov e o I Congresso de Intercâmbio Comercial com as Colónias, em 1934; além da organização do I Cruzeiro, em 1935 a Sociedade de Geografia promoveu a "Semana das Colónias".

Posteriormente ao "período Monteiro" mantêm-se iniciativas relevantes. Em 1938, a visita presidencial às colónias é acompanhada e filmada pela Missão Cinegráfica às Colónias, em que seguiu o "cineasta do regime", António Lopes Ribeiro (1908-1995). Nos anos subsequentes, este lançou vários documentários sobre as colónias além de, em 1940, estrear o segundo e último filme de propaganda explícita do regime, Feitiço do império, estreado durante a Exposição Colonial do Mundo Português.

\section{CRUZEIRO DE (RE)CRIAÇÃO NACIONAL SOBRE NOVO MAPA DO IMPÉRIO}

Assente-se então que a organização, pela revista "O mundo português", da viagem e do seu registo filmado, está subordinada à vontade de projectar, potenciando, a dimensão de Portugal - que, como se escreve no roteiro, "não termina no Algarve" e "são todas as colónias" - e exibir a possibilidade de os portugueses viajarem depressa e comodamente, não obstante a dimensão do império, como turistas (e também como homens de negócios, cientistas e académicos), por uma "nova" cartografia do império. Na Exposição Colonial do Porto usara-se, pela primeira vez, um mapa que sobrepunha o então império português a alguns dos principais países europeus, com o título: "Portugal não é um país pequeno"vi .

A necessidade de projecção, externa mas também interna, vinha de longe e motivara, em parte, a participação portuguesa na I Guerra Mundial, devido aos rumores - que não cessam - de negociações para a partilha das colónias e atenta nas ambições da "nova Alemanha" nacional-socialista. O Acto colonial de 1930, anterior à Constituição do 
Estado Novo de 1933, fora, aliás, a resposta urgente, de Salazar, à cobiça despertada pelas colónias, objecto de pretensões de outros impérios, justificadas pelo deficit colonizador português. E, para projectar o império, nada melhor do que começar com a doutrinação dos futuros homens de ciência e negócios.

Portugal não termina no Algarve; Portugal são todas as colónias. [...] Nada, portanto, como uma viagem oceânica para mostrar o tamanho deste grande país aos seus próprios filhos. E os portugueses precisam disto porque entre eles se vulgarizou a ideia duma pátria pequena. Até por carinho é costume dizer: "Portugal pequenino". Pois temos que nos habituar a dizer: o "grande Portugal". Mas para isso temos que visitar o Portugal que existe espalhado no Atlântico e em África, para não falar já das terras portuguesas da Ásia e da Oceânia (1935: 5).

No roteiro assume-se que o propósito de mostrar que "Portugal não é um país pequeno" esteve subjacente à criação d'O mundo português, pelo Decreto-lei 23482 de 20 de Janeiro de 1934, e à iniciativa de promoção de cruzeiros. Outro desígnio do cruzeiro, sustenta-se, é levar o Portugal continental às colónias. Trata-se de investir os viajantes da responsabilidade de "uma embaixada da terra-mater aos filhos distantes da pátria". Para tal assumia $O$ mundo português ser preciso:

[...] ter bem presente no espírito e no coração a imagem dum Portugal grandioso, redimindo e confiante no dia de amanhã, dum Portugal novamente enérgico, capaz de conquistar o Futuro, sempre orgulhoso do Passado mas sem a tristeza de uma nação saudosa.

Finalmente, o cinema impunha-se como o meio para projectar essa energia conquistadora e a vertigem da viagem rumo ao futuro. E porque o futuro era o que estava em jogo, o público-alvo desta viagem era o da "mocidade académica" da classe dominante.

Com estas viagens convenientemente orientadas por um critério pedagógico, não só se ministra à mocidade académica uma lição prática de geografia, que ela jamais esquecerá, mas também no seu ânimo juvenil se cria a consciência da grandeza de Portugal no mundo. E se daqui possivelmente não resultarem novas vocações para a vida colonial, há-de pelo menos robustecer-se o orgulho e a alegria de ser português, há-de fazer boa sementeira de propaganda das coisas belas do nosso ultramar e hão-de estreitar-se os laços morais que serão a mais forte garantia da unidade do Império.

Foi com estas palavras que o Ministério das Colónias reconheceu a utilidade dos "Cruzeiros de Férias" que tinham como propósito levar estudantes e professores para, segundo o artigo $2^{\circ}$ do Decreto-lei 25555, de 28 de Junho de 1935, "dar a conhecer [...] a extensão, a importância e a riqueza das colónias visitadas", além do objectivo de "estreitar as relações culturais e económicas entre a metrópole e o império ultramarino".

O certo é que este cruzeiro de 1935 terá despertado uma "vocação" para a vida colonial em vários estudantes. Um dos que se veio a notabilizar foi Ruy Cinatti ${ }^{\text {vii }}$ que terá então conhecido e estreitado amizade com Orlando Ribeiro, um dos adjuntos do director cultural do cruzeiro, Marcello Caetano. 
O convite a San Payo afigura-se então como uma tentativa de assegurar a qualidade artística do registo da primeira ${ }^{\text {viii } ~ " e x c u r s a ̃ o ", ~ o r g a n i z a d a ~ e n t r e ~} 10$ de Agosto e 28 de Setembro, para dar a ver a cerca de 200 excursionistas o Portugal de além-mar, num roteiro que incluiu paragens em S. Vicente, Praia, Bissau, Bolama, Príncipe, S. Tomé, Cabinda, Sazaire, Luanda, Porto Aboim, Novo Redondo, Lobito, Moçâmedes, S. Tomé e Funchal. Note-se, porém, que, apenas as visitas a Luanda, Lobito e Moçâmedes duraram mais do que um dia, ficando os excursionistas escassas horas em todos os restantes locais, como pode comprovar-se no roteiro editado e que inclui o regulamento da viagem, etc (1935: 10). Atente-se, porém, nos propósitos da viagem que o referido artigo $2^{\circ}$ do Decreto-lei 25:555 define claramente: "O Cruzeiro terá por fins principais dar a conhecer aos estudantes e professores que nele tomarem parte a extensão, a importância e a riqueza das colónias visitadas e a estreitar as relações culturais e económicas entre a metrópole e o Império Ultramarino".

\section{FILME DE VIAGENS COLONIAL COMO GÉNERO NUMA “CULTURA DE MOBILIDADE"}

O filme I cruzeiro às colónias é um diário de viagem oficial, cujo planeamento e ritmo foi imposto pelo roteiro definido pelo director do cruzeiro, que também dirigia O mundo português, Augusto Cunha (1894-1947), e cuja montagem se ressente do ritmo intenso da deslocação no espaço e repetição do tipo de visitas - sobretudo a roças e fazendas -, que geraram pressão sobre a filmagem. Só em breves e curtos instantâneos se revela, aqui e além, a sensibilidade fotográfica do realizador sem que neste caderno de viagem filmado haja tempo para detalhar o quotidiano ou a vida nas colónias. Repetem-se as chegadas e partidas, as danças em homenagem dos visitantes da metrópole, as recepções oficiais, entre aspectos da viagem por mar, as excursões, em automóvel ou de comboio, apenas com pausas para visitas a explorações agrícolas ou oficinas.

Trata-se, pois, de um filme através do qual a AGC quis transportar os portugueses numa viagem pelo progresso das colónias. Os viajantes do cruzeiro e os espectadores do filme são levados a ver aspectos das paisagens e a organização do trabalho colonial em todos os meios de transporte modernos. A viagem faz-se tanto por picadas, serpenteando pelas florestas e pelas encostas a vencer, às vezes intransitáveis, quanto pelo mar, para se eliminar o além e se sublinhar antes a portugalidade inscrita na paisagem através da igreja, presente há séculos, da casa do administrador ou da roça, num estilo arquitectónico característico, que se repete (como Gilberto Freyre tanto fará notar, em 1953, noutro caderno de viagem, Aventura e Rotina) -, como pelo caminho de ferro de Benguela, prodígio de modernidade.

Formatado pelo protocolo e pelo apertado programa de visitas, constrói-se como uma montagem de sequências em que o registo imposto é o da sucessão de viagens que atestam o domínio do espaço: de barco, primeiro; de carro, para chegar a locais pré- 
-determinados (em S. Tomé, às roças Água Izé, Monte Café, e Rio do Ouro; em Angola, à fazenda Tentativa, à granja $\mathrm{S}$. Luiz e outras fazendas não especificadas, além da Estação Zootécnica e missão na Huíla; no Príncipe, a roças não identificadas); de comboio, no coração de Angola. Impõe-se a exibição da velocidade da viagem - e também, literalmente, da velocidade com que se visitaram certos locais - e do domínio das novas tecnologias, confirmação de Portugal como potência colonial capaz de dominar a natureza, de redesenhar a paisagem, de assegurar o progresso social e económico (neste aspecto atente-se na quantidade de publicidade a empresas coloniais publicada no "roteiro" da viagem) e de o projectar e mostrar ao mundo. A tecnologia do cinema e as das comunicações viárias integram-se, pois, num mesmo contínuo - de aceleração da existência humana, pela potenciação da velocidade com que se atravessa espaço e tempo e de projecção de imagens. De luz e sombras, as imagens de cinema; imagens de poder - um poder demiúrgico -, transversais a todas as novas tecnologias retratadas, sejam de deslocação efectiva no espaço e pelo tempo ou de projecção de luz. O avanço tecnológico, consagração das possibilidades de progresso garantidas pelas teorias evolucionistas, vem, porém, cavar o fosso que separa colonizadores e colonizados. Neste filme-metáfora, as tecnologias, de aceleração e de projecção, mostram os excursionistas num ensaio de dominação da paisagem, numa aceleração consagrada pelo próprio roteiro da viagem, deixando para trás, circulando a pé, com as cargas à cabeça, os naturais das então colónias. Terá sido, também, uma noção desse fosso, ampliado pela projecção, que determinou que o filme não fosse exibido mais vezes?

\section{MOÇAMBIQUE: CULTURA E IMPERIALISMO NO GRANDE HOTEL COLONIAL}

O navio era como um grande hotel. Para passar o maior número de horas em terra era preciso voltar ao nosso dormitório flutuante. Só em Angola se sorteou um grupo de vinte e cinco privilegiados que foram de comboio até Huambo (Nova Lisboa), daí por estrada, até Lubango (Sá da Bandeira), de onde desceram de comboio até Moçâmedes. A estes foram-se juntando outros tantos que conseguiram obter automóveis particulares (Ribeiro, 1978: 24).

Nas vésperas da partida do Moçambique $e^{\mathrm{ix}}$ foi inaugurada a bordo uma exposição de produtos ${ }^{\mathrm{x}}$. A projecção do potencial económico das colónias - dos produtos e também do seu potencial consumidor - não foi descurada pela propaganda, atestando o esforço para integrar o país no movimento imperialista consagrado pela Conferência de Berlim.

Costa Ramos (2014: 190) cita o geógrafo Jean Brunhes para atestar a presciência deste quando, há um século, antecipava um "mundo globalizado pelo movimento da conquista, do comércio e da circulação de capital."

No momento em que, devido à intensidade e à multiplicidade das comunicações, todas as partes do universo são postas violentamente em relação umas com as outras, a humanidade tende para uma certa uniformidade de usos, de necessidades e de hábitos 
quotidianos. O facto económico e geográfico da circulação (a Verkehrskultur ${ }^{x i}$ como dizem os alemães) desempenha um papel tão predominante que, na concorrência mundial, as antigas pequenas unidades económicas que viviam a sua vida própria, com uma inteira independência, produzindo quase tudo de que tinham necessidade, são todos os dias ameaçadas na sua própria existência e dentro de pouco tempo terão desaparecido.(Brunhes, 1913 37)

A listagem de "Industriais e comerciais" que expuseram no Moçambique evidencia que havia expectativa quanto à obtenção de receitas no mercado colonial pelos exibidores, muitos dos quais mostram produtos que não são oriundos das colónias, como a Adega de Colares, a Companhia Agrícola e Comercial dos Vinhos do Porto, A Fosforeira Portuguesa ou a Sociedade Nacional de Fósforos, a Fábrica de Porcelana Vista Alegre, a Kodak, a Vidago, Melgaço \& Pedras Salgadas ou o Grémio do Comércio de Exportação de Vinhos xii. Além da participação do Grémio do Minho Colonial Português e da Sociedade Comercial e Industrial de Produtos Alimentares Tropicais não parece haver, de modo óbvio entre os expositores, empresas "coloniais"xiii. Assinale-se que, se uma parte da publicidade incluída no Roteiro não foi adaptada visando o mercado colonial, há casos em que se denota essa preocupação, como evidencia uma publicidade genérica ao vinho do Porto em que se recomenda tomá-lo com quinino como "maravilhoso antídoto contra as febres de África" ou o da Diogo \& Cia, que se anuncia como de importação e exportação de "Tecidos e artigos vários para permuta com o indígena".

Em Orientalismo, Edward Said propôs que, sem examinar o "orientalismo" como um discurso (Foucault), não é possível entender o modo como a cultura europeia foi capaz de dirigir e mesmo produzir o Oriente política, sociológica, ideológica, militar e imageticamente (1978: 3) $)^{\mathrm{xiv}}$. Esta assumpção de Said pode generalizar-se e aplicar-se ao discurso da portugalidade e, posteriormente, ao luso-tropicalismo. Os cruzeiros às colónias cumpriram uma missão ideologicamente orientada, não descurando a componente cultural. Não é em vão que Cardeira da Silva e Oliveira lhes chamam "cruzeiros de soberania" em "Paquetes do império: O Primeiro cruzeiro de férias às colónias"

Foi Marcello Caetano quem definiu, com Augusto Cunha, o programa cultural e educativo a ministrar no âmbito da "missão pedagógica" a desenvolver a bordo por si e pelos adjuntos, Norberto Cardigos dos Reis ${ }^{\text {xvi }}$ e Orlando Ribeiro. Orlando Ribeiro escreveu que "vivendo a sonhar com viagens desde a infância", teve "a sorte de ser indicado pelo director do Faculdade de Letras de Lisboa (o malogrado filólogo João da Silva Correia)" (1978: 22). Nas suas palavras: "Iríamos mostrar aos outros o que aparecia pela primeira vez aos nossos olhos deslumbrados". O geógrafo comenta criticamente a falta de adesão geral dos professores de Geografia Colonial, leccionada à data nas universidades de Lisboa e de Coimbra, que "preferiram as férias na praia ou no repouso campestre" (1978: 23). A ausência destes foi colmatada, ainda segundo Orlando Ribeiro, por "colonialistas": 
um antigo oficial da marinha, da mais nobre estirpe, que se demitira com o advento da República, saudoso das escalas e das terras onde acompanhara o príncipe D. Luís Filipe ${ }^{x v i i}$; advogados, que conheciam por experiência um mundo chicaneiro; o corifeu do nacionalismo monárquico e autoritário, garante da sobrevivência do império; um herói nacional, que se batera contra os alemães e a tropa preta que enquadravam junto da fronteira do Sudoeste de Angola.

Note-se então que, além da "mocidade académica", Orlando Ribeiro destaca a presença no cruzeiro do "corifeu do nacionalismo monárquico e autoritário" como contraponto à ausência, desinteressada ou simplesmente comodista, dos professores de Geografia Colonial.

Após a partida do Moçambique do Cais da Fundição, em Lisboa, a 10 de Agosto, Caetano, Ribeiro e Cardigos foram ministrando o "Curso de férias" destinado aos estudantes, o qual também era aberto aos restantes viajantes, que poderão ter aderido em quantidade à iniciativa, a avaliar pelo filme de San Payo, que documenta uma aula leccionada pelo futuro Presidente do Conselho, mas também, a 24 de Agosto, pela reportagem do Diário de Notícias que relata que estas eram muito frequentadas pelas "senhoras, que às horas das aulas disputa(va)m os melhores lugares para ouvirem as interessantes lições de História e Geografia coloniais”.

As matérias leccionadas incluíam "Noções sumárias de geografia do continente africano", "O descobrimento da África Ocidental", "História das colónias da África Ocidental", "O mar", "Noções sumárias das Ciências da Colonização" e "Noções sumárias da Administração Colonial Portuguesa". Pedia-se aos inscritos que, nas excursões em terra, apontassem as observações e impressões para posteriormente escreverem relatórios da viagem, alguns dos quais foram publicados em $O$ mundo português. Aos professores cabia examinar criticamente as notas, corrigindo-as e completando-as. $\mathrm{O}$ regulamento do cruzeiro advertia expressamente que entre as impressões não deveriam constar reflexões políticas, pois o regulamento, definindo os deveres dos excursionistas, exigia, na alínea f, que se abstivessem de "discussões de carácter político".

\section{PAISAGENS SEM HOMENS: MOVIMENTO DA CONTEMPLAÇÃO PARA A COMPAIXÃO}

Não terá sido, pois, possível discutir a bordo uma das descobertas feitas em Cabo Verde - a do flagelo da fome - que Orlando Ribeiro descreveu depois em A itha do Fogo e as suas erupções (1945).

A fome não estaria também ausente de Angola. Se, em A colonização de Angola e o seu fracasso, Orlando Ribeiro descreve a paisagem avistada na Huíla é para logo afirmar a necessidade da deslocação, necessária, da contemplação do naturalista para a sua compaixão com os homens e mulheres afectados pela pobreza extrema. O excerto em que descreve a Huíla poderia ser sobreposto às paisagens cinematográficas de San Payo. Com um senão: nestas não se fixa a realidade da seca, comentada por Orlando Ribeiro. 
Moçâmedes fechou o ciclo da variedade das paisagens de Angola, desde a mata densa de N'dalando onde o cafezeiro espontâneo medra no sub-bosque, aos montes-ilhas na subida para o Huambo, às escarpas imponentes na Serra da Chela, ao mato ralo no seu sopé, até aos traços geometricamente puros do deserto do Namibe. Planaltos rasos, vales incisos, vertentes ritmicamente cortadas por cornijas de rochas duras e horizontais, de uma tonalidade entre amarela e cinzenta, e dunas em forma de crescente, de uma pureza de linhas e de cores - o branco das areias listrado por uma pátina arroxeada. Como vegetação, odres, de nome tão sugestivo, e essa incomparável Welwitchia mirabilis, com o seu caule rasteiro em forma de taça para recolher as condensações ocultas e duas folhas rasgadas pelo vento que fazem lembrar tentáculos de um polvo gigantesco (...).

Mas para o geógrafo, nem tudo cabe na contemplação de naturalista. Longe das paisagens belas e inúteis do deserto absoluto, os homens padecem. As terras cultivadas da Huíla haviam sofrido um ano seco. Perderam-se colheitas e gados, gastaram-se reservas alimentares, foi preciso acudir às populações, a um bodo vieram mais de dois centos de famintos, entre pretos e brancos: não há como a pobreza para irmanar raças que, no êxito, tendem a supor-se superiores.

O que o filme de San Payo fixa não é um movimento, recomendado por Orlando Ribeiro, da contemplação para a compaixão. A introdução do factor humano como elemento central à compreensão geográfica, característica distintiva fundamental do trabalho de Orlando Ribeiro, afirma-se pois como o elemento em falta neste filme de viagem, vítima de uma aceleração e de uma cultura do movimento que o torna cego porque vazio de compaixão. Num ou noutro retrato vê-se "voyeurismo" mas não compaixão. Há um olhar fugidio que não se detém, que não vê porque é um olhar-movimento de um filme atormentado e sem consciência da condição de objecto dominado pela cultura do movimento. Se, como propõe Costa Ramos, foi a capacidade de Jean Brunhes de compreender as "culturas de mobilidade e de comunicações" do seu tempo a impor a sua geografia humana fazendo dele um grande defensor da instrumentalização da fotografia e do cinema pela investigação, Orlando Ribeiro tem a consciência de que é preciso acrescentar-lhe a compaixão do investigador, rompendo com a tara positivista dominante. É notável que Brunhes tenha defendido apaixonadamente o cinematógrafo pela capacidade de "registo exacto e perfeito de tudo o que é do domínio da vida" (Brunhes, 1913: 38), antecipando que "ele vai tornar-se cada vez mais num dispositivo de investigações científicas (Costa Ramos, 2014: 190-191) sendo o humanismo de Orlando Ribeiro fundamental para evitar que a ciência e a cultura se tornem reféns do imperialismo. Um certo tipo de cinema, com declinações em vários subgéneros, entre os quais o filme de viagens colonial, serviu projectos imperiais de nações que então construíam para si novos mapas. Devido, porém, à natureza oximórica do cinema, mesmo os filmes de propaganda - por vezes sobretudo estes - expõem, de modo cru, a desumanização dos processos de expansão colonial. O filme de San Payo foi quase certamente "vítima" disso mesmo. Numa bulimia do movimento, no centro de uma cultura de mobilidade, faltou-lhe o movimento mais íntimo, profundo e subtil: da contemplação para a compaixão. 


\section{BIBLIOGRAFIA}

ANÓNIMO (1930). O filme de Angola: O Sr. César de Sá quere [sic] que lhe façam justiça. Cinéfilo, 77. 2 de Fevereiro, 1930.

ANÓNIMO (1935). Diário de Notícias, 24 de Agosto de 1935

ANÓNIMO (1932). Um documentário português. Imagem, 48. 21 de Janeiro, 1932.

ANÓNIMO (1935). Roteiro do $1^{\circ}$ cruzeiro às colónias de Cabo Verde, Guiné, S. Tomé e Príncipe e Angola, iniciativa do Mundo Português. O Mundo Português. A.G.C / S.P.N., Lisboa.

ANÓNIMO (1935). O Mundo Português. A.G.C / S.P.N., Lisboa.

Castro, T. (2013). Viagem a Angola: cinema científico e etnográfico. In M. C. Piçarra \& J. António (Eds.), Angola, o nascimento de uma nação. Vol. 1 O cinema do império. Lisboa: Guerra \& Paz.

Freyre, G. (1954). Aventura e rotina - Sugestões de uma viagem à procura das constantes portuguesas de carácter e acção. Lisboa: Edições Livros do Brasil.

Garcia, J. L. L. (2011). Ideologia e propaganda colonial no Estado Novo: da Agência Geral das Colónias à Agência Geral do Ultramar 1924-1974. Tese de Doutoramento em História, especialidade Histó- ria Contemporânea, Faculdade de Letras da Universidade de Coimbra, Coimbra, Portugal.

Piçarra, M. C. (2013). Azuis ultramarinos: propaganda colonial nas actualidades filmadas do Estado Novo e censura a três filmes de autor. Tese de Doutoramento em Ciências da Comunicação, variante Cinema e Televisão, Faculdade de Ciências Sociais e Humanas da Universidade Nova de Lisboa, Lisboa, Portugal.

Pimentel, J. (2007). Um filme de amigos. In P. Bernaschina (Ed.), Missão botânica transnatural. Angola 1927-1937. Artez: 127-136.

Pimentel, J. (2012). La collection coloniale de la Cinemateca Portuguesa. Journal of Film Preservation, 64, 22-30.

Ramos, J. C. (2014). Atlas da memória e esperança. As tecnologias de informação e comunicação podem ser instrumentos de cidadania dos sujeitos e comunidades de espaços urbanos segregados? Tese de Doutoramento em Geografia. Faculdade de Letras da Universidade de Lisboa, Lisboa, Portugal.

Ribeiro, O. (1978). A colonização de Angola e o seu fracasso. Lisboa: Imprensa Nacional - Casa da Moeda.

Stilwell, P. (1995). A condição humana em Ruy Cinatti. Lisboa: Editorial Presença.

i A partir de 1916 filmou A quadrilha do esqueleto, um policial de longa-metragem; a tragédia A cabana do pai Tomás; O senhor de posição, além de vários documentários.

ii Formado em direcção de fotografia pelo pioneiro Manuel Maria da Costa Veiga, para cuja produtora, Lusitânia Film realizou actualidades. Depois de ter trabalhado com Leitão de Barros num dos primeiros filmes realizados por este, Mal de Espanha (1918), começou a trabalhar para a Invicta Film, realizando vários documentários. Foi aí que assegurou a direcção de fotografia de Mulheres da Beira (1923) de Rino Lupo, tendo no mesmo ano mas para outra produtora, filmado, com Lupo, Os lobos. A partir de 1924 foi produtor independente, realizando vários documentários sobre monumentos portugueses além de filmar actualidades para produtoras internacionais, como a Éclair, Fox News e Paramount News, e de assegurar a direcção de fotografia de várias longas-metragens de ficção. Além de ter fundado, em 1918, uma produtora de documentários e filmes publicitários, a Laboratório Cinematográfico, voltou a colaborar com Leitão de Barros nalgumas das obras de referência deste: Nazaré, praia de pescadores (1929) e Lisboa, crónica anedótica (1930).

iii Antes da encomenda destas obras, que filmes coloniais tinham sido feitos? Poucos e sobretudo de propaganda. O primeiro filme colonial conhecido é de 1909. Trata-se da longa-metragem documental Cultura do cacau, filmada por Ernesto de Albuquerque (1883-1940) em S. Tomé e Príncipe, para responder à campanha internacional, pela Cadbury, de denúncia de trabalho forçado nessa ilha. Ernesto de Albuquerque, de A. Videira Santos, é a única publicação a fornecer elementos sobre a produção desta obra.

iv João César de Sá, "O filme de Angola: O sr. César de Sá quere [sic] que lhe façam justiça”, Cinéfilo, nº 77, 2 de Fevereiro de 1930 e "Um documentário português", Imagem, no 48, 21 de Janeiro de 1932.

v Dela resultaram Primeira exposição colonial portuguesa e O cortejo histórico com a representação de todas as colónias portuguesas, de Aníbal Contreiras e Manuel Luiz Vieira respectivamente. 
vi O mapa foi "organizado" por Henrique Galvão, que veio depois a desviar o paquete Santa Maria.

vii No regresso, Cinatti decidiu que o seu futuro passaria pelas colónias. Stilwell (1995: 33) refere uma carta para Amy Christie, com data de 28 de Novembro de 1935 em que escreveu: "Está assente, irei para África, para Angola, irei para Timor, irei para alguma das distantes províncias do meu Portugal. Oh! Que benção foi para mim estar nesses territórios. Aqueles horizontes largos alargaram a minha visão das coisas" [tradução minha]. Silvino Silvério Marques, futuro governador de Angola, terá sido outro dos alunos marcados por esta viagem.

viii É a primeira excursão pública com fins propagandistas assumidos pela entidade organizadora. No entanto, já em 1929 tinha sido organizada a primeira Missão Académica a Angola, organizada pela Junta de Educação Nacional e dirigida pelo botânico Luís Carrisso, da Universidade de Coimbra. Nela participaram 22 pessoas, entre alunos e professores universitários. A viagem foi registada em A Missão Académica a Angola - Alguns aspectos cinematográficos da viagem (1929, 35 mm, 34 min), filme amador de Maximino Correia, professor de Medicina que nunca filmara antes e que comprou uma câmara de filmar para registar a viagem. Explica Castro (2013: 129-130): "Pouco se sabe sobre a decisão de documentar cinematograficamente a viagem, cujo objectivo não é o de recolher espécimenes botânicos (como para as missões realizadas em 1927 e 1937), mas antes a de realizar 'uma propaganda intensa das colónias, como campo de trabalho, nos meios académicos portugueses' (Carrisso, 1932:51). [...] A missão académica a Angola é verdadeiramente um filme de amador, ou "de amigos", na expressão de Joana Pimentel (Pimentel, 2007:127-136). Mas as instâncias para que remete estão longe de se limitar a uma esfera 'íntima': [...] o filme escolhe registar - e assim memorizar - as marcas mais explícitas da presença colonial: sessões solenes em honra da missão, escolas, vias de comunicação, empreendimentos industriais (como a exploração de diamantes no Dundo), missões. O espaço social no qual se movem Correia e os seus companheiros de viagem é perfeitamente delimitado pelas instâncias oficiais".

ix Um dos navios alemães apreendidos, nos portos portugueses, durante a I Guerra Mundial e que, depois de recauchutado, integrou a frota da Companhia Nacional de Navegação.

x Segundo o roteiro, os expositores que participaram na excursão foram Armando Leão e Silva, Ernesto Pedroso, François Reynaud, Joaquim da Silva Pereira, John Mac Donald Cohin, José Mantua, Manuel Cardoso Pereira, Mário Águia de Pina.

xi Cultura do tráfego ou da mobilidade.

xii Repete-se o modelo ensaiado durante a Exposição Colonial do Porto.

xiii As outras empresas são A Furbana (tecidos de seda), Aurélio António Domingos \& C ${ }^{a}$ Lda (louça de alumínio, latão e alpaca), C. R. Almeida (tapetes), Companhia Nacional Mercantil (calçado e correias), Companhia Portuguesa de Higiene (produtos químicos e farmacêuticos), Consórcio Português de Conservas de Peixe, Grémio do Comércio de Exportação de Frutas, Corporação Mercantil Portuguesa (fibrocimento), Fábrica de Bolachas, Biscoitos e Chocolates "Favorita", Grémio do Comércio de Exportação de Vinhos (vinhos e fruta), Guilherme Graham Júnior \& $C^{a}$ (tecidos de algodão, papel, cartão, etc.), Guimaraens \& $C^{a}$ (vinhos do Porto), Indústrias Portuguesas de Munições, Mário Navega (louças e artigos de ferro esmaltado), Ourivesaria Aliança, Sociedade de Perfumarias Nally, Simões \& Ca (artefactos de malha), Viúva de J. J. Nunes \& Ca (cartas de jogar). Além dos expositores outras empresas anunciaram no roteiro, ajudando ao encaixe necessário para financiamento da viagem (com 150 contos dados pelo governo e os valores das inscrições dos excursionistas).

xiv Culture and imperialism (1993) aprofunda a análise.

xv Se esta não foi a primeira "missão" às colónias, foi a primeira de grande escala e teve sequência, logo em 1937 mas em sentido inverso, com o Primeiro cruzeiro dos estudantes das colónias à metrópole, seguido dos cruzeiros dos velhos colonos, dos cruzeiros da Mocidade Portuguesa e, finalmente, da Fundação Nacional para a Alegria no Trabalho (FNAT).

xvi Nas palavras de Orlando Ribeiro, "um dos mais distintos estudantes de Geografia e dos melhores docentes da matéria no liceu”.

xvii Primeiro e último príncipe português a visitar as colónias. 